\author{
University of Sydney \\ Royal Prince Alfred Hospital \\ Sydney, Australia
}

\begin{abstract}
References
1. Cao C, Manganas C, Horton M, Bannon $\mathrm{P}$, Munkholm-Larsen S, Ang SC, et al. Angiographic outcomes of radial artery versus saphenous vein in coronary artery bypass graft surgery: a metaanalysis of randomized controlled trials. J Thorac Cardiovasc Surg. 2012 Aug 4. [Epub ahead of print]

2. Souza DS, Johansson B, Bojo L, Karlsson R, Geijer H, Filbey D, et al. Harvesting the saphenous vein with surrounding tissue for $\mathrm{CABG}$ provides long-term graft patency comparable to the left internal thoracic artery: results of a randomized longitudinal trial. J Thorac Cardiovasc Surg. 2006;132:373-8.

3. Lopes RD, Hafley GE, Allen KB, Ferguson TB, Peterson ED, Harrington RA, et al. Endoscopic versus open vein-graft harvesting in coronary-artery bypass surgery. N Engl J Med. 2009;361:235-44.

4. Davis Z, Jacobs HK, Zhang M, Thomas C, Castellanos Y. Endoscopic vein harvest for coronary artery bypass grafting: technique and outcomes. J Thorac Cardiovasc Surg. 1998;116:228-35.
\end{abstract}

http://dx.doi.org/10.1016/ j.jtcvs.2012.12.078

\section{CLINICAL IMPLICATIONS RELATED TO PREOPERATIVE DETECTION OF STAGE IA LUNG ADENOCARCINOMA To the Editor:}

We read with interest the article by Tsutani and colleagues. ${ }^{1}$ They aimed to determine clinical predictors of nodal involvement in stage IA lung adenocarcinoma and successfully identified that tumor size $<0.8 \mathrm{~cm}$ and maximum standardized uptake value $<1.5$ are predictive for stage N0 status. We would like to discuss the following interesting items.

One of the most important indications for sublobar resection is the absence of nodal disease (ie, stage N0), which is usually preoperatively investigated by computed tomography (CT) and positron emission tomography (PET)-CT scan. ${ }^{2}$ A more accurate evaluation of nodal status can be obtained by intraoperative nodal dissection with frozen section, as reported by the authors. ${ }^{1}$ However, the intraoperative evaluation of every hilar and mediastinal nodal station appears to be too difficult to be routinely performed in clinical practice. To avoid this, Tsutani and colleagues identified 2 factors statistically significant for preoperative prediction of NO status. In particular, it is remarkable that these 2 parameters are easily achievable by the chest CT and PET-CT scan that are always performed when staging the disease of every patient with lung cancer.

We work daily with patients who should be excluded from surgery because their poor general health conditions or advanced age strongly advise against lobectomy. Tsutani and colleagues' findings should be particularly useful with these patients because they allow clinicians to preoperatively determine patients in which lobectomy can be avoided and sublobar resection with nodal sampling is enough. This increases the number of candidates for surgery.

Another item that we would like to underline is that the chance to preoperatively determine $\mathrm{N} 0$ status and therefore to plan a sublobar resection allows surgeons to understand the proper access to adopt. In particular, the possibility of performing a wedge resection with nodal sampling should increase the chance to perform video-assisted thoracic surgery, ${ }^{3}$ increasing once again the number of candidates for surgery.

One more interesting point is that tumors determined to be $<0.8 \mathrm{~cm}$ or with maximum standardized uptake value $<1.5$ are characterized by a minor pathologic invasiveness and therefore are related to a better disease-free survival after sublobar resection.

Finally, we have 1 suggestion regarding the technique used in PET-CT scan for lesions affected by physiologic motion as pulmonary nodules. We suggest the use of respiratory gating ${ }^{4}$ because this method results in lesion volumes closer to those assessed by CT and improves measurements of tracer uptake.

Alessandro Baisi, $M D^{a}$

Matilde De Simone, $M D, P h D^{b}$ Ugo Cioffi, $M D, P h D^{b}$

${ }^{a}$ Thoracic Surgery Unit Azienda Ospedaliera San Paolo

\author{
Milano \\ University of Milan \\ Milan, Italy \\ ${ }^{b}$ Department of Surgery \\ Fondazione IRCCS Ca' Granda \\ Ospedale Maggiore Policlinico \\ Milano \\ University of Milan \\ Milan, Italy
}

\section{References}

1. Tsutani Y, Miyata Y, Nakayama H, Okumura S, Adachi S, Yoshimura M, et al. Prediction of pathologic node-negative clinical stage IA lung adenocarcinoma for optimal candidates undergoing sublobar resection. J Thorac Cardiovasc Surg. 2012;144:1365-71

2. Okada M, Koike T, Higashiyama M, Yamato Y, Kodama K, Tsubota N. Radical sublobar resection for small-sized non-small lung cancer: a multicenter study. J Thorac Cardiovasc Surg. 2006;132:769-75.

3. Sienel W, Dango S, Kirschbaum A, Cucuruz B, Horth W, Stremmel C, et al. Sublobar resections in stage IA non-small cell lung cancer: segmentectomies result in significantly better cancer-related survival than wedge resections. Eur J Cardiothorac Surg. 2008;33:728-34.

4. Werner MK, Parker JA, Kolodny GM, English JR, Palmer MR. Respiratory gating enhances imaging of pulmonary nodules and measurement of tracer uptake in FDG PET/CT. Am J Roentgenol. 2009; 193:1640-5.

http://dx.doi.org/10.1016/ j.jtcvs.2012.12.082

\section{Reply to the Editor:}

We are grateful for the letter by Baisi and colleagues regarding our study, ${ }^{1}$ and we are delighted by their thoughtful insights into our results. We appreciate their viewpoint that 2 parameters (solid tumor size $<0.8 \mathrm{~cm}$ on high-resolution computed tomography [HRCT] or a maximum standardized uptake volume [SUVmax] $<1.5$ on 18F-fluorodeoxyglucose positron emission tomographycomputed tomography [PET-CT]) for predicting no nodal metastasis are easily achievable by the chest CT and PET-CT scan that are always performed in staging the disease of every patient with lung cancer. ${ }^{2}$

Generally, clinical physicians measure tumor size according to the TNM Classification of Malignant Tumors (TNM) by including the ground-glass opacity (GGO) components visualized on HRCT. We have found ${ }^{3,4}$ that 